\title{
Bill and Melinda Gates honored with Lasker Bloomberg Public Service Award
}

\section{T}

he 2013 Lasker Bloomberg Award for Public Service recognizes the extraordinary impact made by Bill and Melinda Gates toward improving global public health through the work of their foundation. Bill Gates made his fortune as one of the giants of the modern computer industry; today he and his wife Melinda may be equally well known for their worldwide work in philanthropy. Founded in 2000, the Bill \& Melinda Gates Foundation is now the largest private foundation in the U.S. (1). The foundation has provided more than $\$ 26$ billion in grant funding for all of its programs since inception and in recent years has invested nearly $\$ 2$ billion annually for global health projects alone (2). What started as a simple desire to help those less fortunate blossomed into a bold organization, willing to take on seemingly insurmountable public health challenges.

The concept behind the Bill \& Melinda Gates Foundation began to take shape in the late nineties. Bill Gates recalled, "For my wife Melinda and me, the problem of global health inequity became visible fifteen years ago, when we saw a simple pie chart in the newspaper breaking down the major causes of death among children. One of the bigger slices of the pie, representing 500,000 dead children annually, was labeled: rotavirus. I had never heard of rotavirus. Melinda had never heard of it. It turns out it is the leading cause of diarrhea, preventable with a vaccine that only children in rich countries were getting. Our reaction was somewhere between disbelief and disgust. How could we not have seen even the barest outlines of this tragedy?"(3). This observation set in motion a new sense of urgency in Bill and Melinda Gates and started them on the ambitious path of trying to make a difference in public health and save lives.

Bill and Melinda Gates (Figure 1) may not have been public health experts at the time, but over the course of the next few years, they assembled a team of experts in science, medicine, and policy and undertook an initiative to address the biggest killers in the developing world. Dr. Tadataka (Tachi) Yamada, President of the Global Health Program at the Bill \& Melinda Gates Foundation from 2006-2011, recently told the JCI, "Because of the sincerity of their commitment and the depth of their passion, Bill and Melinda really established not just a foundation but a new way of thinking about how to address inequities in health care." Yamada credits the foundation for bringing the resources and partnerships needed to convert independent global health projects into coordinated efforts and accelerating implementation campaigns. Yamada said, "I think the Gates Foundation brought a sense of urgency, passion, and commitment that allowed the world to be more ambitious in a way, to solve some very difficult problems that seemed almost beyond solution. In addi-

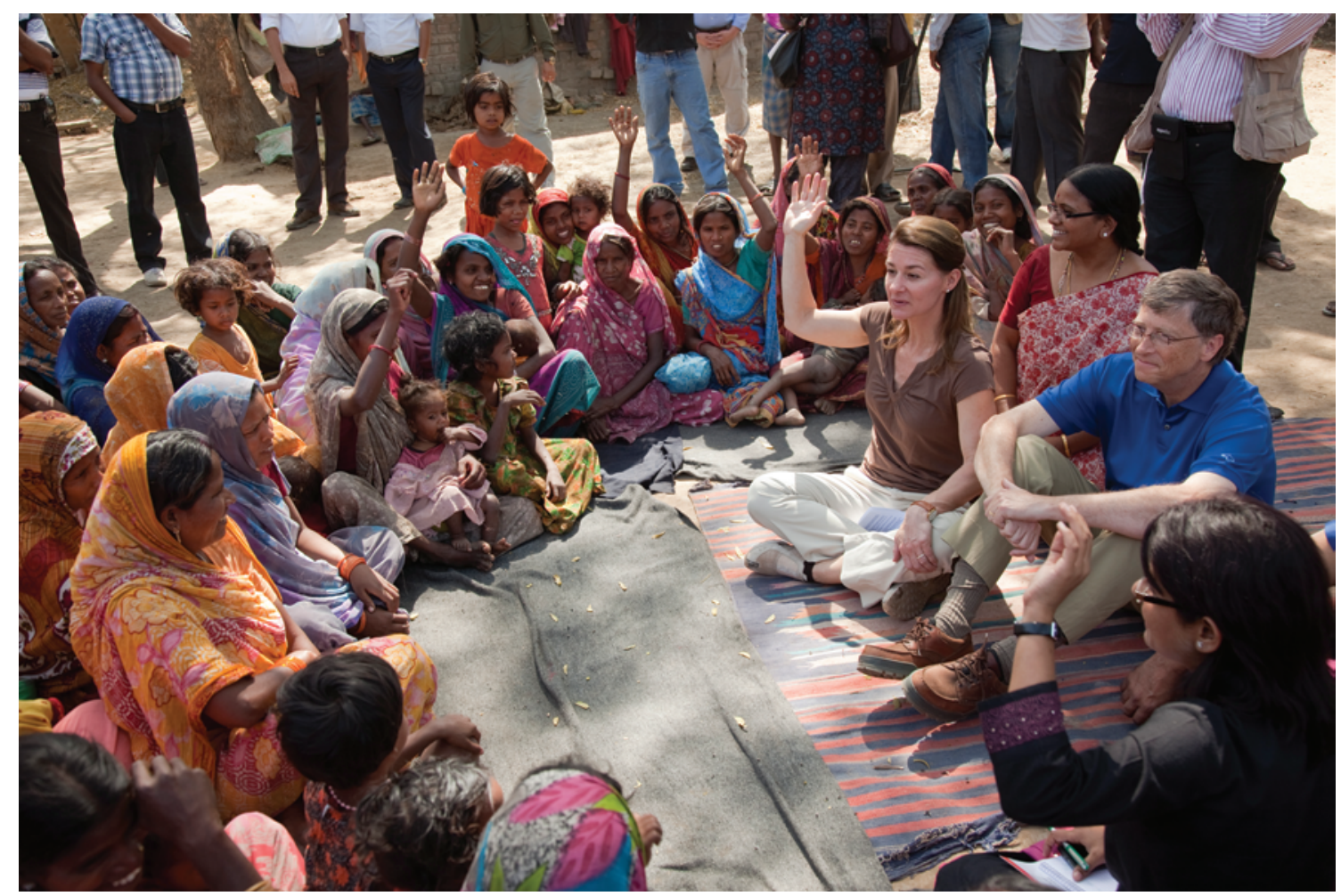

Figure 1

Bill and Melinda Gates, recipients of the 2013 Lasker Bloomberg Public Service Award, on a recent trip to Bihar, India. Image courtesy of the Bill and Melinda Gates Foundation. Copyright Bill \& Melinda Gates Foundation/Prashant Panjiar. 


\begin{tabular}{l} 
Table 1 \\
Major global health programs funded \\
by the Bill \& Melinda Gates Foundation \\
\hline Polio eradication \\
Vaccine delivery \\
HIV/AIDS \\
Malaria \\
Tuberculosis \\
Neglected and other infectious diseases \\
Enteric and diarrheal diseases \\
Pneumonia \\
Maternal, newborn and child health \\
Family planning \\
Nutrition
\end{tabular}

tion, the Gates Foundation invested very substantially in research and development for new solutions to health care problems."

\section{Seeking innovations in HIV research}

The Bill \& Melinda Gates Foundation focuses on several strategic areas (Table 1), including HIV/AIDS, malaria, diarrheal diseases, and other infectious diseases (2). According to the World Health Organization (WHO), over 95\% of HIV-infected individuals are in developing countries, and over 28 million people live with HIV in subSaharan Africa (4). Early on, the foundation committed huge resources to its HIV program, and to date, more than $\$ 3.5$ billion in grants has been pledged for HIV/AIDS projects alone (5).

In addition to programs to boost prevention and treatment efforts, the Bill $\&$ Melinda Gates Foundation remains committed to vaccine research and development. Dr. Barton Haynes, Director of the Duke Human Vaccine Institute at the Duke University School of Medicine, told the JCI, "For HIV research, the Gates Foundation support has been remarkably important for the field, beginning in 2005, when the Collaboration for HIV Vaccine Development (CAVD) program began. Since that time, the foundation has supported a number of new technologies and vaccine candidates that have moved forward to clinical trial testing." In addition to the grant support that the foundation has provided for HIV research, Haynes also credited the Bill \& Melinda Gates Foundation for its role in facilitating access to emerging technologies in developing countries through global access requirements of their grantees.

In his research, Haynes is examining an important obstacle that has prevented HIV vaccine development; specifically, his group seeks to uncover why the body typically fails to produce broadly neutralizing antibodies in response to acute HIV infection. In addition, the Haynes lab is working to develop new strategies for vaccine development that might induce antibodies that recognize multiple strains of HIV (6). Haynes believes that a strength of the Bill \& Melinda Gates CAVD program has been a willingness to fund high-risk, highreturn research. "In the case of support for my research here at Duke, their support has been transformational. The Gates Foundation has funded high-risk work of ours that has made a major difference in our ability to move our work forward on the role of host factors in control of protective neutralizing antibodies." In particular, the Bill \& Melinda Gates Foundation funded research from the Haynes lab that demonstrated immune tolerance control of some specificities of broadly neutralizing antibodies $(7,8)$. "The foundation has also funded the production of clinical trial materials of a novel mosaic vaccine for testing in phase I trials in man and, in doing so, has sped up the development and assessment of HIV candidate vaccines," said Haynes.

\section{Pushing malaria research forward}

A common thread among strategic projects of the Bill \& Melinda Gates Foundation is a willingness to work with partner organizations and across disciplines to promote a more effective and rapid outcome. Dr. Christopher Plowe, Professor of Medicine at the University of Maryland and Leader of the Malaria Group at the University's Center for Vaccine Development, studies the genetic diversity of malaria and the molecular basis of malaria resistance to combination therapies. Plowe received funding from the WHO through a grant from the Bill \& Melinda Gates Foundation to work with a network of research partners in Southeast Asia, and he spoke to the JCI about how these funding partners were able to proactively coordinate and maximize efforts in studies that were ongoing. Plowe recalls that several independent groups were in the early stages of planning clinical trials of the efficacy of artemisinins, and the funding partners at the foundation and WHO established a network between these research teams. Plowe was asked to coordinate genomic aspects of the project, examining resistance to the artemisinins at sites along the Thailand-Myanmar border and in western Cambodia and Bangladesh.
The funding agencies helped facilitate the collection of samples during the course of the trials that the Plowe group could then use to extract malaria genomic DNA for their genome-wide association study. "If we had gone through more traditional funding bodies, we would have had to wait and try to start a whole new set of studies, and it would have easily been two or three years later before we had the results," Plowe said. His group recently reported the identification of genomic loci linked to delayed clearance of the malaria parasite (9). Plowe credits the foundation for its role in coordinating regional efforts to have a much broader impact than individual, investigator-led research projects could have made.

According to a recent WHO estimate, there are approximately 219 million cases of malaria each year and about 660,000 deaths, with the majority of cases occurring in children in Africa (10). The Bill \& Melinda Gates Foundation has committed nearly $\$ 2$ billion in malaria grant funding to date; however, this infusion of funding is only part of the solution. The foundation has also sought to establish loftier goals for the entire research community. In 2007, Bill and Melinda Gates met with malaria researchers and global health leaders to issue a call to develop a roadmap for malaria eradication (11). This bold goal has been transformative, though at the time many in the field were skeptical of its feasibility. "At the point when Bill and Melinda Gates, in conjunction with the WHO, issued this call for global malaria eradication, the malaria community had not been thinking that way, not even as a long-term aspirational goal. There was no immediate universal acceptance of the idea that this was going to be the right direction. But now the community has really come around to the notion that we should be eliminating malaria country by country, with a longterm goal of eradication," Plowe told the JCI. Plowe believes that the Bill \& Melinda Gates Foundation can truly be commended for injecting a new level of energy into malaria research and control and providing a new focus on driving down malaria transmission with a goal of eradication.

\section{Finding solutions to urgent problems} Perhaps what is most impressive about the work of the Bill \& Melinda Gates Foundation has been its ability to take on these seemingly intractable problems and see appreciable progress. A unique form of bacterial meningitis, meningitis $\mathrm{A}$, is par- 
ticularly prevalent in sub-Saharan Africa, with outbreaks from 1995-2004 resulting in 700,000 cases and 60,000 deaths (12). In 2001, the Bill \& Melinda Gates Foundation began funding for the Meningitis Vaccine Project, with awards to the Program for Appropriate Technology in Health (PATH) and the WHO, with collaboration from African health ministers and the Serum Institute of India (13). Tachi Yamada recalled to the JCI, "There was a series of meningitis A epidemics that were sweeping across central Africa and killing many, many people. It is a very scary kind of disease because it hits suddenly, and you could be dead overnight. Even if you survived, you could be left with seizures or functional deficits." The vaccines available at the time did not induce preventive immunity and could only be used after infection. Additionally, strains of meningitis A that were resistant to those vaccines had begun to emerge, further highlighting the need for the development of new vaccines to prevent future epidemics (12). The Bill \& Melinda Gates Foundation was able to identify key intellectual property that existed at the time and help facilitate the release of this intellectual property. Tadataka Yamada told the JCI, "The Gates Foundation helped set up a program to develop vaccines and worked with PATH, through the Meningitis Vaccine Initiative, which enlisted the support of the Serum Institute of India. The goal of the program was that the vaccine would work the first time and for a long time, and it was supposed to cost less than fifty cents. They set out this ambitious project, and seven years later the vaccine was launched." The vaccine, known as MenAfriVac was launched in 2010 in Burkina Faso. Early this year, the WHO reported that cases of meningitis A were at their lowest in ten years, following the immunization of over 100 million people in ten African countries since the vaccine became available (14). This amazing success story illustrates the ambitiousness that the Bill and Melinda Gates Foundation has infused into the global health community. Their work has shown that with financing, a serious commitment, and the formation of critical partnerships, results can be achieved within a few years.

\section{The work has just begun}

While there is much to celebrate about the accomplishments of the foundation, from Bill and Melinda Gates' perspective, this is no time to rest on their laurels. Since
2000, the mortality rates due to malaria have decreased by more than $25 \%$ globally (10), yet the disease continues to exact a devastating toll in the developing world. At the 2011 Malaria Forum, Melinda Gates remarked, "When I reflect on the progress since 2000, I am filled with optimism about what we can accomplish next. I say what we can accomplish because, while today's advances show us what's possible, they are not an accurate predictor of what will happen tomorrow. What matters is our staying power. We need to keep on seizing the opportunity to make new progress against malaria every single day.” Without a doubt, her comments apply not only to malaria, but to the many strategic initiatives that the Bill \& Melinda Gates Foundation is pursuing. Enormous challenges face the global health community, from malaria and polio eradication to vaccine development for tuberculosis and HIV, among many others. When asked about his time working with Bill and Melinda Gates, Yamada told the JCI, "From them and also certainly from the experience of seeing children in the field in dire straits, I gained a much deeper sense of urgency about what I was doing on a day-to-day basis. Bill and Melinda really exude this sense of urgency, this sense that every minute counts. More than a few times when things were slowing down, Bill would remind us that children were dying every day because we weren't moving fast enough. That fundamentally changes your perspective about how you do things every day." It is this drive that continues to propel the organization forward.

In its push to move forward, the foundation has renewed its call for improved measurements of accountability for their programs and the programs of their partner organizations (15). "The Gates have never been comfortable that they were doing good things just because they were spending money; it's been very important to them to make sure that the money is actually having an impact," Yamada said. The foundation also continues to emphasize the importance of partnerships and innovative thinking in tackling some of the world's biggest health challenges. In 2008, the Bill \& Melinda Gates Foundation initiated the Grand Challenges Explorations grants, a program intended to encourage new ways of thinking and to foster unconventional solutions (16). Yamada said the philosophy of the foundation is that, "If you start thinking that small iterations on previ- ous thinking will get you to your goal, you're probably wrong. You really have to think outside the box, challenge dogma, be willing to fail, but really force yourself to move beyond the obvious to what is really novel and potentially game changing in the service of public health." More than 850 Grand Challenges Explorations grants have been awarded, and promising projects are eligible for larger follow-on funding. Notable past grant challenges included a call to build a better (and more enjoyable) condom that might be more widely used and to reinvent the toilet for areas without access to water and sewer system hook-up $(17,18)$. The most recent challenges solicited new approaches for neglected tropical diseases and the interrogation of antimalarial compounds (19). This investment in innovative approaches emphasizes the belief of Bill and Melinda Gates that profoundly new ideas are needed to solve the world's most vexing global health challenges.

\section{A new kind of philanthropy}

Over the last fifteen years, Bill and Melinda Gates have ushered in a new era of modern philanthropy. As Yamada told the JCI, "The thing that is different about the Gates, as opposed to most other philanthropists in the past, is that they've given their money in the prime of their lives. And they are putting their energy, their enthusiasm, their knowledge, and pure passion into this work." They are not merely financially investing in the issues, but they are active participants in developing the strategic plan for their organization, forming the necessary partnerships, and advocating for progress in global health. Through their tireless work, there has been a fundamental shift in how the global health community approaches problems, and millions of lives in the developing world have been improved. The 2013 Lasker Bloomberg Public Service Award recognizes the extraordinary impact of Bill and Melinda Gates, an accolade that is truly well deserved.

\section{Sarah Jackson}

1. Top 100 U.S. Foundations by Asset Size. Foundation Center Web site. http://foundationcenter.org/findfunders/topfunders/top100assets.html. Updated August 10, 2013. Accessed August 17, 2013.

2. The 2011 Bill \& Melinda Gates Foundation Annual Report. The Bill \& Melinda Gates Foundation Web site. http://www.gatesfoundation. org/ /media/GFO/Documents/Annual $\% 20$ Reports $/ 2011$ Gates $\% 20$ Foundation $\% 20$ Annual\%20Report.pdf. Accessed August 14, 2013. 3. Bill Gates' prepared remarks for Dimbleby Lecture. 
The Bill \& Melinda Gates Foundation Web site. http://www.gatesfoundation.org/Media-Center/ Speeches/2013/01/Bill-Gates-Dimbleby-Lecture. Updated January 29, 2013. Accessed July 31, 2013.

4. $2007 \mathrm{WHO} / \mathrm{UNAIDS}$ estimates for HIV/AIDS. The World Health Organization Web site. http://www. who.int/immunization/topics/hiv/en/index1. html. Accessed August 14, 2013

5. HIV Strategy Overview. The Bill \& Melinda Gates Foundation Web site. http://www.gatesfoundation.org/What-We-Do/Global-Health/HIV. Accessed August 14, 2013

6. Haynes BF, Kelsoe G, Harrison SC, Kepler TB. B-celllineage immunogen design in vaccine development with HIV-1 as a case study. Nat Biotechnol. 2012; 30(5):423-433.

7. Verkoczy L, et al. Autoreactivity in an HIV-1 broadly reactive neutralizing antibody variable region heavy chain induces immunologic tolerance. Proc Natl Acad Sci US A. 2010;107(1):181-186.

8. Verkoczy L, et al. Induction of HIV-1 broad neutralizing antibodies in 2F5 knock-in mice: selection against membrane proximal external region-associated autoreactivity limits T-dependent responses. J Immunol. 2013;191(5):2538-2550.

9. Takala-Harrison S, et al. Genetic loci associated with delayed clearance of plasmodium falciparum following artemisinin treatment in Southeast Asia. Proc Natl Acad Sci U S A. 2013;110(1):240-245

10. Malaria Fact Sheet. The World Health Organization Web site. http://www.who.int/mediacentre/ factsheets/fs094/en/. Updated March 2013. Accessed August 14, 2013.

11. Bill and Melinda Gates Call for New Global Commitment to Chart a Course for Malaria Eradication. The Bill \& Melinda Gates Foundation Web site. http://www.gatesfoundation.org/Media-Center/ Press-Releases/2007/10/Chart-a-Course-forMalaria-Eradication. Updated October 2007. Accessed August 14, 2013

12. Enhanced surveillance of epidemic meningococcal meningitis in Africa: a three-year experience. The World Health Organization Web site. http://www. who.int/wer/2005/wer8037.pdf. Updated September 16, 2005. Accessed August 14, 2013.

13. Statement on the Launch of New Meningitis Group A Vaccine. The Bill \& Melinda Gates Foundation Web site. http://www.gatesfoundation.org/Media-Center/Press-Releases/2010/12/ Statement-on-the-Launch-of-New-MeningitisGroup-A-Vaccine. Updated December 2010. Accessed August 14, 2013.

14. New vaccine drives Africa meningitis cases to lowest in decade. Reuters UK Web site. http://uk.reuters. com/article/2013/06/06/us-africa-meningitiswho-idUKBRE95518Z20130606. Updated Jun 6, 2013. Accessed August 14, 2013

15. 2013 Annual Letter from Bill Gates. The Bill \& Melinda Gates Foundation Web site. http:// annualletter.gatesfoundation.org/\#nav= section 18 slide $=0$. Updated January 2013. Accessed August 14, 2013.

16. Overview of Grand Challenges in Public Health. The Grand Challenges in Public Health Web site. http://www.grandchallenges.org/about/Pages/ Overview.aspx. Accessed August 17, 2013.

17. Bourin L. Gates wants geeks to build a better condom. CNN Web site. http://www.cnn.com/2013/03/25/ health/bill-gates-condom-challenge. Updated March 26, 2013. Accessed August 17, 2013

18. Sutter JD. Gates Foundation: 'We need to reinvent the toilet'. CNN website. http://www.cnn. com/2011/TECH/innovation/07/19/toilet.design. gates/index.html. Updated July 26, 2011. Accessed August 17, 2013.

19. Grand Challenges Explorations: Share Your Great Idea. The Bill \& Melinda Gates Foundation Web site. http://www.gatesfoundation.org/mediacenter/press-releases/2012/09/grand-challengesexplorations-share-your-great-idea. Updated September 2012. Accessed August 17, 2013. 